\title{
Optimisation model for industrial complex competitiveness: a path to sustainable innovation process
}

\section{Vadim V. Krivorotov, Alexey V. Kalina, Zhanna S. Belyaeva* and Sergey Ye Erypalov}

Graduate School of Economics and Management,

Ural Federal University,

Mira Str. 19, i-419, 620002-Yekaterinburg, Russia

Email: v_krivorotov@mail.ru

Email: alexkalina74@mail.ru

Email: zhanna_belyaeva@yahoo.com

Email: ese62@rambler.ru

*Corresponding author

\begin{abstract}
Business entities of all forms and origin face the necessity to foster new management approaches in order to promote its excellence. Sustainability is a key issue for organisations nowadays as they increasingly acknowledge that their practices have social and/or environmental consequences. Multi-stakeholder systems such as industrial complexes/clusters seek to raise competitiveness by integrating new innovative business models and appropriate responsibility in various fields of operations. These managerial technologies require a novel outlook at the optimisation model of the numerous competitive forces and its evaluation. In light of this, it is imperative that new methodologies and frameworks to facilitate the understanding of sustainability concepts in the business environment are to be developed as innovation approach. The framework suggested in the paper helps to outline guidelines on evaluating the nature and process of innovative and sustainable competitive strategy considering many indicators influencing industrial complexes and its environment.
\end{abstract}

Keywords: innovation; organisational competitiveness; sustainability management; sustainable development; optimisation model; industrial complex.

Reference to this paper should be made as follows: Krivorotov, V.V., Kalina, A.V., Belyaeva, Z.S. and Erypalov, S.Y. (2016) 'Optimisation model for industrial complex competitiveness: a path to sustainable innovation process', World Review of Entrepreneurship, Management and Sustainable Development, Vol. 12, Nos. 2/3, pp.254-269.

Biographical notes: Vadim V. Krivorotov is a full-time Professor, Head of the Department of Industry and Energy Systems Economics at the Graduate School of Economics and Management, Ural Federal University (Russia, Yekaterinburg). His research area is competitiveness and industrial complexes economics.

Alexey V. Kalina is a PhD in Technical Sciences. He is a full-time Associate Professor at the Department of Industry and Energy Systems Economics, Graduate School of Economics and Management, Ural Federal University. His research field covers competitiveness measurement and modelling. 
Zhanna S. Belyaeva is a full-time Associate Professor at the International Economy Department, Graduate School of Economics and Management, Ural Federal University (Russia, Yekaterinburg), leader of Global Social Responsibility Excellence Center. She is EMBRI Country Director for Russia. Her main research fields are competitive development and global social responsibility models, and international business sustainable development strategies.

Sergey Ye Erypalov is a part-time Associate Professor at the Department of Industry and Energy Systems Economics, Graduate School of Economics and Management, Ural Federal University. His research interests are in the field of competitiveness and industrial complexes economics.

This paper is a revised and expanded version of a paper entitled 'Sustainability and innovation to increase corporate competitiveness: optimisation model' presented at 7th Annual Conference of the EuroMed Academy of Business 'The Future of Entrepreneurship', Kristiansand, Norway, 17-18 September 2014.

\section{Introduction}

In this paper, we attempt to develop a framework for the competitiveness theory toward creating sustainable managerial innovation within industrial complexes. We argue that sustainability of industrial complexes is nowadays increasing due to effective use of optimisation innovative models based on systematic benchmarking of industry indicators, including both operational efficiency, market adaptability and responsible internal and external development.

In this paper, we propose to measure the competitiveness of an industrial complex as an integrated indicator, formed under the influence of innovation adaptability of a business entity. One of the most important determinants defining sustainable development of a company or an industrial complex (comprising big companies, forming production technological cycle, its sales and marketing mix, and also post-service system of the goods) is its responsible business development model towards business, social and ecological environment. We argue competitiveness and sustainability are mutually reinforcing concepts that force management techniques towards general innovation growth.

\section{Theoretical background for competitive and sustainable business model}

The concept of sustainable enterprise is related to the general approach to sustainable development, originally enunciated in the Brundtland report, as an approach which postulates a holistic, balanced and integrated perspective on development and which has subsequently been elaborated and endorsed through declarations emanating from a number of high-level global development forums. Thus, in contrast to narrowly defined, traditional perspectives which depict enterprises in terms of linear input-output relationships centred solely on maximising short-term economic value, an integrated approach to sustainable business development takes a more holistic, integrated and 
long-term view, which makes a stylised distinction of what in practice are overlapping and interdependent operational and policy spheres (ILO Report, 2007). That also reflects internal competitiveness relations with industrial-(territorial) complexes (Russian analogues of industrial cluster), which are based on the mutually engaged in multiple-bottom-line model of business connections defined by geographical concentration of competing and partnering firms, specialised suppliers, supporting service providers, firms in related branches and related institutions (e.g., universities, standardisation agencies, trade associations).

Competitiveness is the key characteristic of economic entities from the point of view of their operation in a turbulent environment (Putsis and Dhar, 1998). Competitiveness is an integral indicator that is formed under the influence of numerous factors affecting all aspects of a socio-economic system. At the same time, operational activity and development policies should make room for efforts to maximise the competitiveness of the socio-economic system that in most of the available approaches is measured by the combination of indicators, with each of them reflecting this of that side of competition and competitive advantages of the socio-economic system.

The concept of clusters as an optimal business model was developed by many international leading scientists, including: 'American school' representing global issues of nation competitiveness depending on different local terms (Porter, 1998; Porter and Kramer, 2011; Enright, 2002); 'British school', concentrating on the transitional corporation drivers and its geographical location competitiveness (Dunning, 1993), industrial clusters and value-based chains and 'European school' developing among other fields learning and knowledge transfer economy and national/regional system of innovation (Solvell et al., 2003; Lundvall and Johnson, 1994) and quality index for economy conditions by Reinert (2009).

The concepts of Porter and Enright are used today by most academics and practitioners, who agree that the key feature of clusters is the possibility and a deliberate policy of competition among its constituent elements. In the meantime the global trends environmental, social, political, and technological - continue to shift the foundations of the existent current business models, incremental innovation will become less effective in enabling companies, industries and whole economies to adapt and succeed. There is an urgent need for fundamentally different approaches to value creation.

Business sustainability is one of those business behavioural models. The linkage between competitiveness and sustainability is embodied in the literature on financial and organisational performance (Orlitzky et al., 2003). Other approaches to competitiveness and sustainability address the issue by strategically exploiting resources and capacities. This is usually embedded in the resource-based notion of the firm (Hart, 1995). Other perspectives such as stakeholder management require companies to act responsibly towards consumers, investors, and government, as well as to manage benefits to motivate, attract, and retain employees that create value for the company (Freeman, 2004; Porter and Kramer, 2011). An aligned business and sustainability strategy reflects the nature and extent of the opportunities associated with sustainable development as it relates to the creation of value for the firm (Aigner and Lloret, 2013). While creating a new value via raising internal and external competitiveness seems to be an essential innovation, it might require a cognitive evaluation and knowledge transfer, further we briefly explore the existent methodology on industrial competitiveness measurement. And the measurements 
should take into consideration the call for new business innovation models that are based on sustainability in social, financial, ecological vectors ensuring diverse impact on various stakeholders (Clinton and Whisnant, 2014).

Despite growing interest in sustainable development, the relationship between environmental or social sustainability and national competitiveness has been only marginally explored (Bilbao-Osorio et al., 2013). The so called advanced economies tend to force sustainable business models systematically, using among others legal forces systematically, while in emerging economies, sustainability is still not very much related with competitiveness business driver (Belyaeva, 2013). Global competitiveness report 2014-2015 adjusted the frameworks builds on the flagship global competitiveness index (GCI), adding up two additional pillars: the social and the environmental sustainability pillar.

Nevertheless, the economic component of sustainable development still leads the business processes involved in value creation. The new business model is grounded on efficiency and sustainable practices applied to the economic environment, such as: limitation of the mineral resources used, energy and water saving, diminution of the polluting emissions, waste management, extending the environmental management systems, increases in corporate social responsibility (Zott et al., 2011). At the same time, operational efficiency incorporates a comprehensive assessment of enterprise's activities which subsequently raise the efficiency of its production factors, and hence interrelations with stakeholders. In order to attain operational efficiency a company needs to minimise redundancy and waste while leveraging the resources that contribute most to its success and utilising the best of its workforce, technology and business processes. More and more the social and ecological dimensions have become important objectives in the management of the economic processes. The legal responsibility is also important to be considered competitive and entails expectations of legal compliance and playing by the 'rules of the game'. From this perspective, society expects business to fulfil its economic mission within the framework of legal requirements. But while regulations may successfully coerce firms to respond to an issue, it is difficult to ensure that they are applied equitably (Pratima, 2002). And finally, mutual sources of research support the idea that companies with good records of corporate social performance have a competitive advantage in attracting employees (Backhaus et al., 2002). Indeed, the innovation driver should be based on four interconnected key elements, such as customer value proposition, profit formula, and the closely linked key resources and processes, which altogether grow the rules, norms, and success metrics of a business (Johnson, 2010). Thus, the mentioned sources of the enterprise's innovative competitive development directly influence all sustainability factors (Asheim and Isaksen, 2002); hence it is interesting to approach the methodological guidelines for systemic management of corporate competitiveness to bring innovation into the standard business model.

Carayannis et al. (2014) suggested that innovative character of the competitive business model emerges from the high level of business-processes adaptability and aims at the optimisation of the coexistence, cooperation, and coordination of resilience and robustness. Just as organisation design is important to resilience and robustness, so is innovation a documented resilience enabler. 


\section{Measurement of industrial complexes competitiveness}

Thus, the competitiveness of industrial complex's performance impacts the entire management and production system. A crucial operational factor for any industrial complex is the location that implies the geographical proximity of integrated organisational entities, resulting with lower production costs and stronger competitive advantage of products due to shared technological, research, educational, environmental and social infrastructure. A system like this requires innovative business-model design and tailored methodology for assessing its competitiveness.

Industrial complex sustainable competitiveness is a multifaceted socio-economic system allowing the complex as whole and its key companies to maintain and ensure a steady growth of their economic performance and simultaneously acceleration of quality of life and level of income in the territory of operation. The industrial complex is a socio-economic system characterised by a wide scale of social, economic and environmental activities that consists of a large number of organisations and interorganisational connections, which might be in conflict (Krivorotov et al., 2013). Sustainability requires resolving the conflict between the various competing goals and involves the simultaneous pursuit of economic prosperity, environmental quality and social equity famously known as three dimensions (triple bottom line) with the resultant vector being technology (Hasna, 2007). Competition within the market is vital for business and society to understand and test how to best meet people's needs with more sustainable solutions (Holliday and Pepper, 2001). Markets liberate ingenuity by encouraging experimentation and rewarding those ideas that meet stakeholder's needs and aspirations most efficiently. Approaches to corporate development have traditionally focused on project-level technical assistance and finance. Today if a business does not explore ecooriented opportunities within its products, processes or services, it does not learn much from its environment focused business activities. When it foregoes its opportunities to learn from environmental challenges, opportunities to build ecocentric organisational culture may also slip away (Banerjee, 2002). Obviously, effective social dialogue is a means for fostering better workplace relations and helping to nurture sustainable industrial complex development.

Sustainable competitive advantages are continuous accumulation of some small, and even unimportant, short-term competitive advantages. The strategic positioning is based a lot with two key ingredients. One of them represents corporate relations with the external environment. It may be interpreted as its ability to adapt to the organisational domain, its level of innovation management, which is crucial for any modern market-oriented industrial complex. This component characterises the corporate adaptability to the conditions of the external environment, the flexibility of its response to the environmental changes.

We focus on the adaptability of industrial system, which builds up enterprises' sustainable development. The adaptability is understood as a constant innovation activity that involves all business processes both internally and externally, and also affects key stakeholders. It is the second driver - efficiency, we argue, which provides and sustains the conditions for adaptability. Innovation and adaptability together form the necessary and sufficient conditions for the enterprise's strategic market positioning (Santo, 1990).

The high level of adaptability of the enterprise depends on strategy formulation tailored for the particular stakeholder, partner and its individual needs and opportunities to choose from the variety of competing companies in the market according to the scale 
of preferences. These preferences can be arranged according to specified criteria, reflecting mainly basic consumer characteristics, their price and quality, now have undergone significant changes towards integrated diversity and complexity.

Considering mentioned above challenges for of the corporate and industrial competitiveness management system, we suggest the following logic of interaction of factors and sources of the industrial complex competitiveness (Figure 1). The critical factors will be described in details in part 3 of the presented paper.

Figure 1 Management of corporate and industrial complex competitiveness

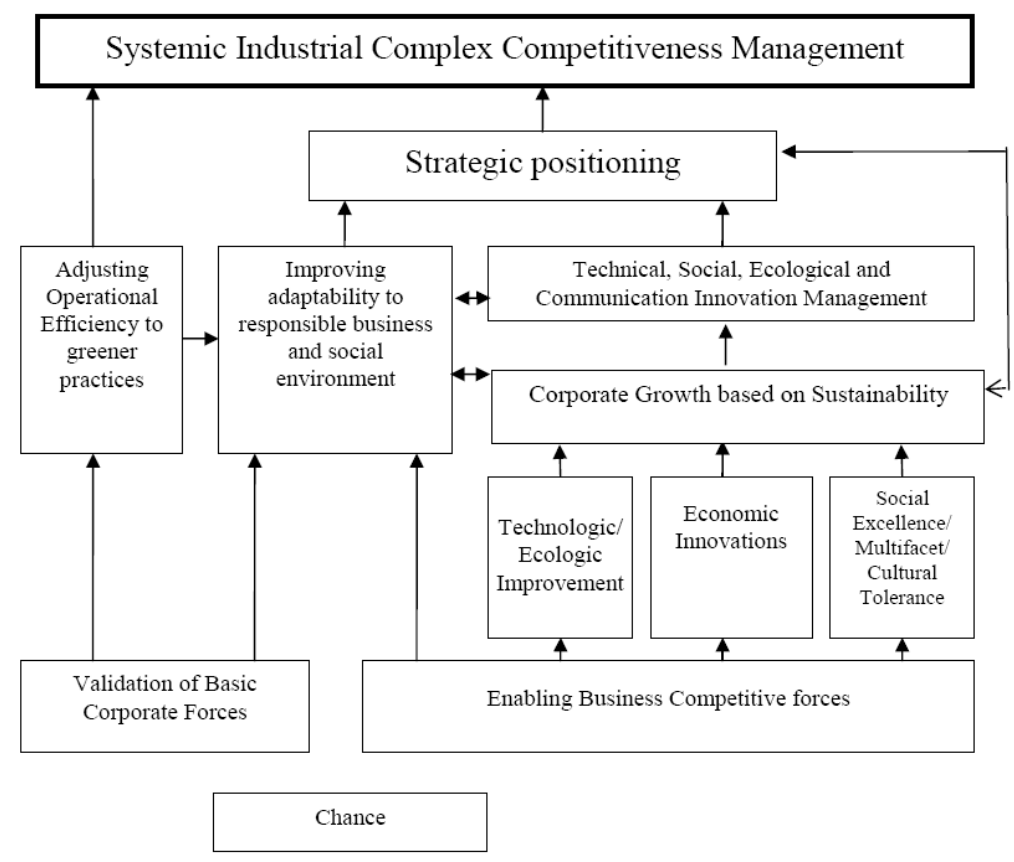

The measurement of industrial competitiveness has been of particular concern to researchers. Various theories, methods and indices have been tested and adopted gradually towards conceptualising industrial competitiveness. There are two categories of the measurement of industrial competitiveness including show-indicators methods (revealed comparative advantage index, trade competition index, the terms of trade index, intra-industry trade index and domestic resource cost coefficient) and multi-factor comprehensive evaluation methods (World Economic Forum, The International Institute for Management Development and Porter's Diamond Model) (Peng, 2013).

It should be noted that competitiveness assessment methods applicable to various entities (from standalone companies to big corporations, regions and states) as well as frameworks for building competitive strategies and advantages, assessing competition effects have been extensively developed in the works of many scholars in regard to modern socio-economic systems (Ahn, 2002; Badinger, 2013).

Some researchers have also disputed that benchmarking indicators, adopting for instance EFQM and BSC, can bring positive effects reflected in the explicitness of the accepted company strategy and its connectedness with the activities on all levels, with a 
clearly defined responsibility for achieving the set objectives and ensuring suitable resources for achieving them (Podobnik and Dolinšek, 2008).

Despite the relatively thorough elaboration of competitiveness assessment methods they seem to have certain downsides. Specifically, it could be described as follows: the methods are only aimed to define the investment attractiveness with no details of internal competitiveness potential; the data is based on expert evaluations, which makes the results fairly conventional with a high degree of subjectivity; most of findings are limited to only assessing individual project competitiveness.

As a result, today there is no universal methodological apparatus that would provide a comprehensive in-depth competitiveness assessment of an industrial complex to reveal and develop its competitive advantages and eliminate weaknesses. The development of such a methodology becomes one of the critical tasks of ongoing research on competitiveness. Obviously, the leading companies are those that can adapt their strategy to a more diverse market needs. The challenge of today requires the ability to initiate demand for upgraded services and goods to lead the market, and in the same time develop internal social responsibility in order to be sustainable and competitive creating innovation and social added value. Any organisational structure might be irrelevant according to the new Microsoft CEO Nadella (2014), because no competition or innovation is going to respect those boundaries. Everything now is going to have to be much more compressed in terms of both cycle times and response times.

The level of meeting the above-mentioned criteria sets preconditions of enterprise positioning in the market. High adaptability corresponds to the adequate market share, while mistakes and miscalculations, irrelevant actions to maintain the required adaptability will inevitably affect the loss of former market position. Also it is significant to follow the results of multi-stakeholder dialogue, which can open new facets for adaptability, which could bring on societal competitiveness. Sustainability is forcing corporations to deal with, such as the subject is very "complex, interrelated, and secular, and that the corporate sector will play a key role in solving the long-term global issues related to sustainability" (Berns, 2009). This is also applicable to industrial complexes, so it adapts its components to better ecological standards and practices in order to be competitive. Furthermore, embracers see sustainability as a means to produce wealth by obtaining new customers and increased profits. Cautious adopters are primarily focused on short-term benefits that can be easily measured, such as reducing energy consumption and decreasing waste. Although embracers' and cautious adopters' motives vary for sustainability strategies, economics, environmental issues and stakeholder management are drivers that directly align with the proposed CSR definition (Haanaes et al., 2011).

The logical understanding of assessing the effectiveness of the industrial complexes market positioning can be formalised applying its characteristics in the system of «adaptability - efficiency» strategy, there would be four types of companies (Figure 2).

1 Companies with low adaptability and efficiency due to the lack of a clear strategic development plan can be attributed to the problem category, and their disappearance from the market might be just a matter of time, unless the attitude towards innovation management is changed.

2 Companies with passive efficiency and high level of market adaptability result from applied strategy of economy of scale, which is provided by a well-developed technology. However, leadership positions are defined by equipment maximum production lifecycle. 
3 Companies with low market adaptability, while efficiency rate is rather high. It is not rare, when innovation activity does not bring adequate returns because of the needless market ideology, therefore the updates of production processes do not result in their embodiment in the mass product. Eventually, the miscalculations in the strategic marketing 'dilute' highly developed innovation, making it ineffective.

4 Strategic leaders - the innovation management based on high adaptability and efficiency intersects globally with the structure of production, human resources management, marketing and promotion strategy, social and ecological responsibility.

Figure 2 «Adaptability - efficiency» matrix

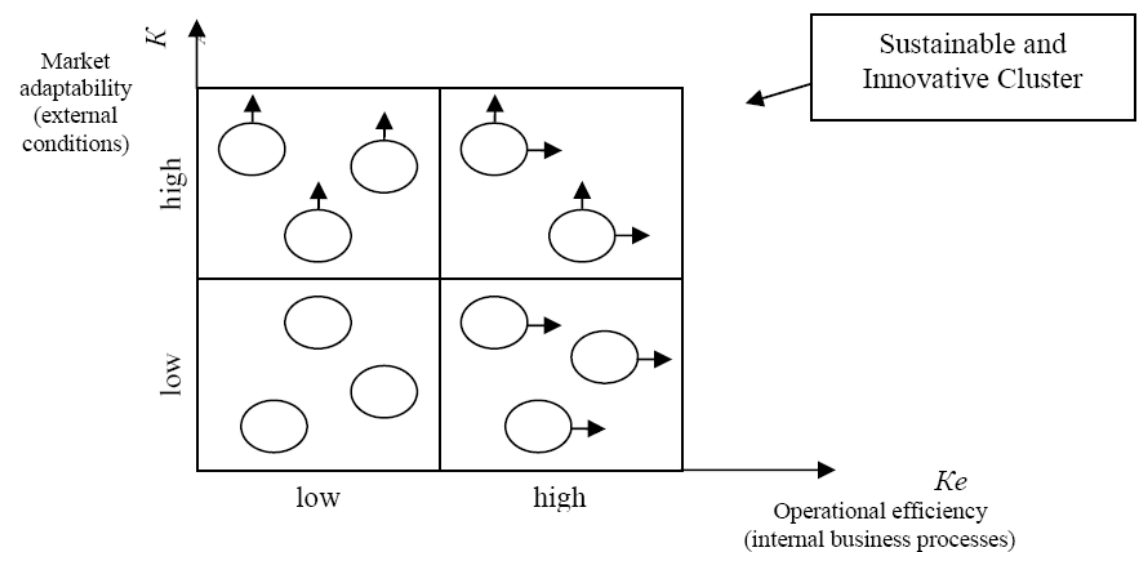

Table 1 Sustainable and innovative development effects

\begin{tabular}{|c|c|c|c|c|}
\hline Economic effect & $R \& D$ effect & $\begin{array}{c}\text { Resource-based } \\
\text { effect }\end{array}$ & Social effect & Ecological effect \\
\hline $\begin{array}{l}\text { - Profit- } \\
\text { innovation and } \\
\text { license } \\
\text { activities } \\
\text { - Sales volume } \\
\text { growth } \\
\text { - Production } \\
\text { quality } \\
\text { increase } \\
\text { - ROI and ROA } \\
\text { increase }\end{array}$ & $\begin{array}{l}\text { - New types of } \\
\text { production } \\
\text { - New } \\
\text { equipment } \\
\text { facilities } \\
\text { - New } \\
\text { technologies } \\
\text { - IT share } \\
\text { - Increased } \\
\text { levels of } \\
\text { automation } \\
\text { products } \\
\text { - Improving } \\
\text { organisational } \\
\text { level of } \\
\text { production } \\
\text { and labour }\end{array}$ & $\begin{array}{l}\text { - } \begin{array}{l}\text { Increased rates } \\
\text { of return on } \\
\text { assets }\end{array} \\
\text { - Accelerated } \\
\text { turnover of } \\
\text { working } \\
\text { capital } \\
\text { - Increase in } \\
\text { labour } \\
\text { productivity } \\
\text { - Reduced } \\
\text { material and } \\
\text { energy } \\
\text { production } \\
\text { Reduced } \\
\text { complexity of } \\
\text { production } \\
\text { processes }\end{array}$ & $\begin{array}{l}\text { - } \begin{array}{l}\text { Income } \\
\text { growth }\end{array} \\
\text { - } \begin{array}{l}\text { Labour } \\
\text { workplace } \\
\text { safety }\end{array} \\
\text { - Working } \\
\text { environment } \\
\text { - HR } \\
\text { qualification } \\
\text { growth } \\
\text { - Social values } \\
\text { satisfaction } \\
\text { - HR turnover } \\
\text { reduction }\end{array}$ & $\begin{array}{l}\text { - } \begin{array}{l}\text { Reduction of } \\
\text { air pollution }\end{array} \\
\text { - } \text { Reducing } \\
\text { waste } \\
\text { production } \\
\text { - Producing } \\
\text { environment- } \\
\text { friendly goods } \\
\text { - Improved } \\
\text { ergonomic } \\
\text { working } \\
\text { conditions } \\
\text { - Reducing } \\
\text { environmental } \\
\text { pollution fines }\end{array}$ \\
\hline
\end{tabular}


Thus, the most important role for sustainable competitive organisation is performed by innovative technological processes, product updates, improvement of production and labour organisation methods, formation of an adequate management system, implementation of ecotechnologies, etc. Implementation of these measures is aimed at amplification of innovative activity, as well as enhancement of an operating efficiency and market adaptability. Taking the above into consideration, the initial selection of innovative activities is logical to be made on the basis of an evaluation matrix, reflecting the degree of impact of a certain innovative change on the enterprise's indicators of operational efficiency and market adaptability (Table 1).

\section{Analytical frameworks for industrial complexes competitiveness analysis}

The desired methods as presented above call for an integral competitiveness index that combines various internal and external economic, social, technological, ecological, innovative characteristics of the industrial complex, allowing to prospect possibilities for its development.

We suggest the following principles to design such an index to measure the industrial complexes competitiveness.

1 Identification of industrial complex current competitive advantages and

'bottlenecks', approving existent indicators of the industrial complex sustainability

(using industry benchmarks). In this case the considered indicator might be used as

the key development target (Krivorotov et al., 2013).

2 Hypotheses are build around sample in terms of sustaining a certain level of competitiveness and shaping its advantages, quantitative and qualitative testing of the industrial complex competitiveness at the current and prospective stage of its development.

2 The future competitive strategy scenario of the industrial complex development is based on a set of alternatives suggesting management tactics guidelines actions to foster innovation and sustainability in order to increase competitiveness of the industrial complex, as well as assessing and validating the existent levels of competitiveness.

To measure the competitiveness with the proposed integral index- $C_{P C}$-we suggest the following equation:

$$
C_{P C}=\sqrt[n]{\prod_{i=1}^{n} C_{P C, i}}
$$

1 A module of indicators of competitiveness of a industrial complex $\left(C_{m I}\right)$ :

- index of the natural resource capacity and available mineral reserves of the industrial complex $\left(C_{P C 1}\right)$

- index of market demand for key products of the industrial complex $\left(C_{P C 2}\right)$

- index of the operational efficiency of the core companies of the industrial complex $\left(C_{P C 3}\right)$

- index of industrial and financial capacity $\left(C_{P C 4}\right)$ 
- index of innovation performance and the novelty of products $\left(C_{P C 5}\right)$

- index of environmental safety and energy efficiency of the companies making up the industrial complex $\left(C_{P C 6}\right)$

- index of restrictions and risks to the development of the industrial complex $\left(C_{P C 7}\right)$.

2 A module of indicators of competitiveness of territorial infrastructure and social environment $\left(C_{m 2}\right)$ includes and not limited to:

- index of infrastructure and service sector development $\left(C_{P C 8}\right)$

- index of the state of the social environment and demographic potential of the home area of the industrial complex $\left(C_{P C 9}\right)$

- index of limitations and risks to the development of the territorial complex $\left(C_{P C 10}\right)$.

$C_{P C}$ and its elements provide the basis for devising initiatives and programs aimed at increasing the competitiveness of the industrial complex and its constituent parts. On the other hand, the indicators provide decision-making information to possible interested investors. The calculation of $C_{P C, i}$ is based on benchmarking the indicators of the industrial complex's competitiveness against corresponding indicators of the baseline model

$$
C_{P C, i}=\frac{V_{P C, i}}{V_{b a s e, i}}
$$

where

$V_{P C, I} \quad$ value of indicator $i$ of the competitiveness of the industrial complex

$V_{\text {base }, i}$ benchmark value of competitiveness indicator $i$.

When using equations (1)-(2), the benchmark model of $i$-industrial complex has $C_{P C}$ and $C_{P C, i}$ equal to 1 . In this case all values of $C_{P C, i}$ exceeding 1 signify a higher level of competitiveness. $C_{P C, i}$ below 1 means that the industrial complex competitiveness is below benchmark.

Each of the above major competitiveness indicators is decomposed to the lower level indicators of competitiveness, characterising specific properties and characteristics of the analysed industrial complex in terms of benchmarking its current competitiveness in the industry and achieving competitive advantage.

The data is to be retrieved from financial and non-financial reports published by the companies embedded in the industrial complex, it is available from goskomstat (Russian statistical agency) ( $80-85 \%$ of needed data), which significantly increases the practical implication for management. The remaining qualitative indicators could be based on the expert evaluation (8-12 top and middle-management level experts). The ecological stability of the territorial industrial complex could be calculated using wide range of quantitative apparatus (e.g., Edgeman and Eskildsen, 2012). The suggested methodology is universal and can be used (subject to appropriate adjustment of particular indicators of competitiveness) for any production facilities, regardless of their activity or specialisation. 
The suggested methodological framework has been tested on some industrial oil complexes in Russia as well as big national companies, oil industrial complexes operating in the Udmurt Republic (UR), Bashkortostan (BR) and Perm Territory (PT) (Figure 3).

Figure 3 Dynamics in the aggregate competitiveness index of the oil complexes

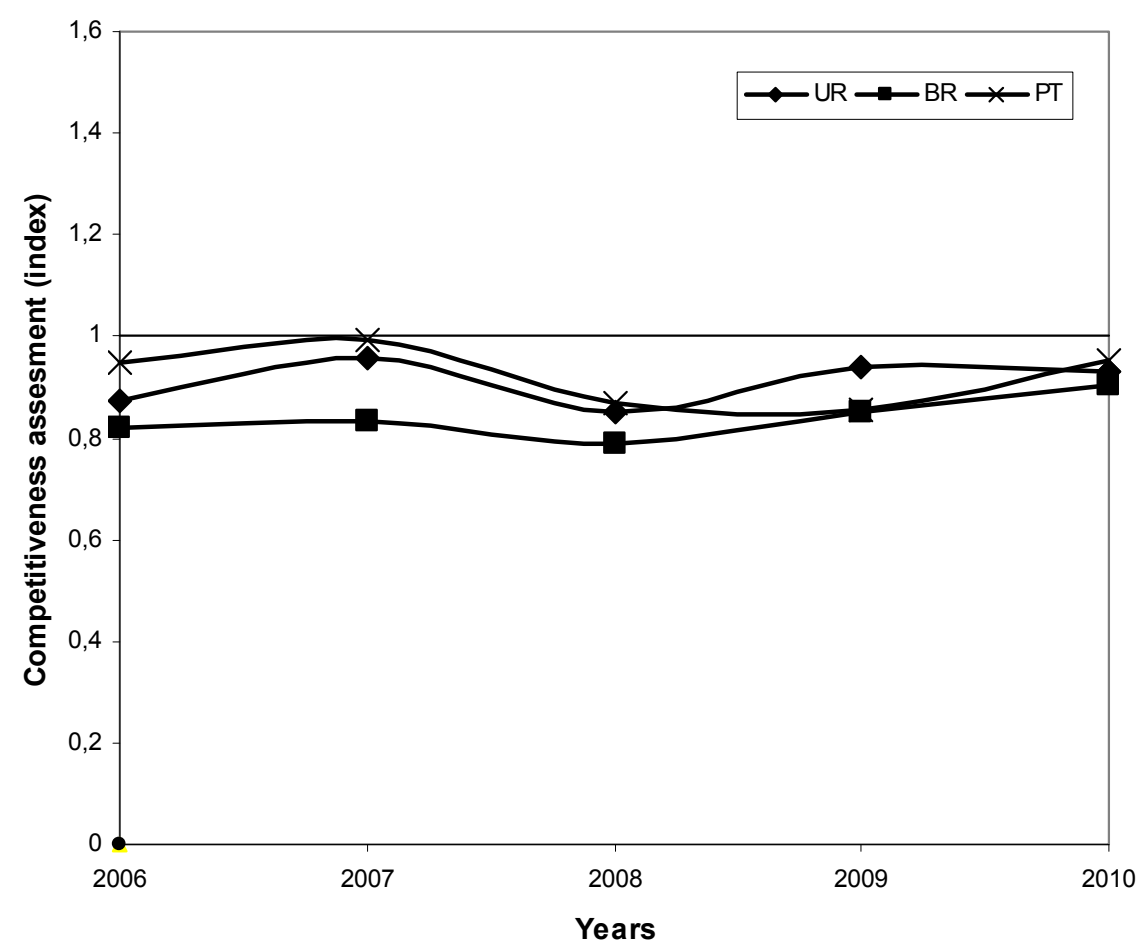

The analysis reveals low level of competitiveness in the industry. The results were used by the top-management to improve general development strategy and control the revealed weak and borderline points of effectiveness. Using suggested framework the complexes identified key performance indicators to monitor in order to achieve sustainability in all three areas ecological, social and economic compliance. A lot of these new indicators were aimed to adjust business development strategy to innovation development strategy. The operating performance strategy aimed at the improvement of the internal business processes, while market adaptability strategy take into account and positively change external conditions for the functioning of an economic entity.

\section{Optimisation model of competitiveness' management enhancement}

As it was mentioned above the criterion to define the priority in the industrial complex strategy actions and assessment should be based on open-system set of indicators, each of them is quantified and requires some adjustment. A comparison of these figures provides some clear organisational guidelines whether to start upgrading the industrial complex operating efficiency, or its market adaptability; it allows ranking the contents of planned 
innovative changes. The next stage is to examine selected activities for their compliance with production capacity, its resource potential, and level of staff efficiency, established organisational culture, and green politics. Based on matrix-resource modelling we evaluate compliance of innovative activities with the above mentioned criteria. In this form of assessment innovations under evaluation are placed vertically in the matrix, and existing financial, economic, labour, information and other resources of the enterprise are put horisontally (Table 2).

Table 2 Matrix-resource model for evaluation of innovations

\begin{tabular}{lccccc}
\hline \multirow{2}{*}{$\begin{array}{l}\text { Types of } \\
\text { resources }\end{array}$} & \multicolumn{4}{c}{ Innovations under evaluation } & $\begin{array}{c}\text { Restrictions on types } \\
\text { of resources }\end{array}$ \\
\cline { 2 - 5 } & $h_{1}=C_{1} X_{1}$ & $h_{2}=C_{2} X_{2}$ & $\ldots$ & $U_{n}=C_{n} X_{n}$ & $\sum P_{1 j} X_{j} \leq P_{1 \Phi}$ \\
$P_{1}$ & $P_{11} X_{1}$ & $P_{12} X_{2}$ & $\ldots$ & $P_{1 n} X_{n}$ & $\sum P_{2 j} X_{j} \leq P_{2 \Phi}$ \\
$P_{2}$ & $P_{21} X_{1}$ & $P_{22} X_{2}$ & $\ldots$ & $P_{2 n} X_{n}$ & $:$ \\
$:$ & $:$ & $:$ & $:$ & $:$ & $\sum P_{m j} X_{j} \leq P_{m \Phi}$ \\
$P_{m}$ & $P_{m 1} X_{1}$ & $P_{m 2} X_{2}$ & $\ldots$ & $P_{m n} X_{n}$ & $\sum$ \\
\hline
\end{tabular}

The completed matrix is an optimisation task, formulation of which is as follows. It is required to maximise information about the study of $n$-dimensional area described by the unknown quantities of the innovations under consideration $\left(X_{j}\right)$, provided the limited amount of resources $\left(P_{i}\right)$, considering optimality criterion $\left(C_{j}\right)$, which can be defined as an average expert evaluation of the significance of each innovation for the enterprise:

$$
\begin{aligned}
& F\left(U_{j}\right)=\sum_{j=1}^{n} C_{j} X_{j} \rightarrow \max , \sum_{j=1}^{n} P_{i j} \cdot X_{j} \leq P_{i \Phi}, \\
& X_{j}= \begin{cases}0, & \text { if the innovation is not implemented } \\
1, & \text { if the innovation is implemented }\end{cases}
\end{aligned}
$$

$X_{j}$ values, which can be obtained by solving the problem, help to model a program of innovation, backed by necessary resources for its implementation. It should be noted that the current task in the above interpretation differs from the classical optimisation task. First of all, it concerns the solution obtained. In classical optimisation problem as a result of its solution optimal allocation of resources among all considered innovative projects is obtained, which is not correct from the standpoint of practical implementation, since any innovation project $X_{j}$ requires resources to be defined in advance for its implementation. Therefore, their partial allocation is not enough for realisation of the project. In the interpretation of form (3) only the most relevant and backed with resources will be implemented.

The suggested approach aims to provide the following innovative and easy to assess techniques, including quantitative methodology that allows comparing several sustainable development scenarios based on competitiveness level for industrial complex; a holistic system of various development criteria of the industrial complex; the method is an 'opensystem' allowing easy adjustment of $C_{P C, i}$ indicators depending on the goal of estimations; equation (3) can pull together measurement results for specific aspects of the 
industrial complex's work that have been obtained through various methods and algorithms.

\section{Discussions and further research}

This study contributes to the literature in providing a novel approach to the theoretical evaluation of industrial complexes competitiveness. It extends existing methodology of competitiveness evaluation by analysing the previous research and filling its gaps using triangulation and adding sustainability and innovation indicators. The comprehensive evaluation of the innovation activities impact considers all possible effects on competitiveness, including economic, research, resource-based, social, economic, ecological enhancements, must be analysed in a close relationship. Mentioned above interrelation determines the interdependence of these effects and some artificiality of its differentiation. The main difference is in the nature of these effects and the time to obtain the expected result. If businesses through sustainable reforms achieve lower material and energy production (resource effect) and lowers its cost, hence increases its competitiveness, this leads to an economic effect in the form of additional profit.

We used the reshaped Porter Diamond Model to adapt it for raising sustainability and competitiveness of an industrial complex. The described model can be used to evaluate compliance of planned innovations with the level of management of any type of organisation. In this case, management functions and its implementation level evaluated by experts' estimations, that are placed in the matrix instead of the resources. For example, a result of working conditions improvement is followed by improved safety and reduced loss of working time (social effect). Ii is a direct social responsible approach to doing business right in the advanced economies, although it is still called the innovative approach in the emerging economies. Today's successful sustainability executive is leading what can best be called a sustainability insurgency inside their organisation. It is an insurgency that breaks the bounds of job description, budget constraints and the limits of 'moral influence' (Unruh, 2014). Its goal is simple: to alter the way business is done in every function and unit of the company.

The considered value chain contributes into one integral effect, resulting with a clear sustainable competitive strategy of the industrial complex. Another important task of applied studies in this field is to adapt the methodology to specific conditions of industrial complexes taking into account their production profiles and competitive environment.

So, the authors consider the proposed approach to the selection of prospective innovation projects, taking into account required resources for their implementation, to be universal. It could be applied to organisations of any form of ownership, organisational and legal forms.

The objective function of the optimisation procedure is suggested to select better solutions over poorer solutions while using the maximum gain of the integral index of competitiveness as a result of project implementation, which is a significant difference from the classical formulation of the problem, which usually focuses on achieving the maximum economic benefit, ignoring the many other aspects of the industrial complex activity. As a consequence, the authors proposed a model of selection of optimal portfolio of industrial complexes based on a comprehensive analysis of various aspects of its 
activities (e.g., Table 1, Table 2), which can significantly improve the quality of the result.

The possibility to track the comprehensive record of the conditions and restrictions that determine the selection or rejection of the analysed projects as well as model to estimate projects timing based on the given cash flow are the main advantages of the proposed optimisation model.

The principal contribution of this paper is to provide a comprehensive and integrative theoretical framework for defining competitive strategy of today industrial complex or organisation. Future research should involve the development and validation of the model to include empirical testing of bigger sample.

\section{References}

Ahn, S. (2002) Competition, Innovation and Productivity Growth: A Review of Theory and Evidence, OECD Working Papers, No 317, Economic Department.

Aigner, D.J. and Lloret, A. (2013) 'Sustainability and competitiveness in Mexico', Management Research Review, Vol. 36, No. 12, pp.1252-1271.

Asheim, B.T. and Isaksen, A. (2002) 'Regional innovation systems: the integration of local 'sticky' and global 'ubiquitous' knowledge', Journal of Technology Transfer, Vol. 27, No. 1, pp.77-86.

Backhaus, K.B., Stone, B.A. and Heiner, K. (2002) 'Exploring the relationship between corporate social performance and employer attractiveness', Business and Society, Vol. 41, No. 3, pp.292-318.

Badinger, H. (2013) 'Measuring the world economy', The World Economy, Vol. 36, No. 1, pp. $12-30$.

Banerjee, S.B. (2002) 'Organisational strategies for sustainable development: developing a research agenda for the new millennium', Special Issue, Australian Journal of Management, Vol. 27, No. 1, pp.105-117.

Belyaeva, Z.S. (2013) 'Transformation processes of the corporate development in Russia: social responsibility issues', System Practice and Action Research, Vol. 26, No. 6, pp.485-496.

Berns, M. (2009) 'The business of sustainability: Findings and insights from the first annual business of sustainability survey and the global thought leaders' research project', MIT Sloan Management Review [online] http://sloanreview.mit.edu/reports/thebusiness-of-sustainability/ (accesses 5 March 2015).

Bilbao-Osorio, B., Blanke, J., Campanella, E., Crotti, R., Drzeniek-Hanouz, M. and Serin, C. (2013) 'Assessing the sustainable competitiveness of nations', The Global Competitiveness Report 2013-2014 [online] http://www.weforum.org/content/pages/ sustainablecompetitiveness (accessed 20 January 2015).

Carayannis, E.G., Grigoroudis, E., Sindakis, S. and Walter, C. (2014) 'Business model innovation as antecedent of sustainable enterprise excellence and resilience', Journal of the Knowledge Economy, Vol. 5, No. 3, pp.440-463, doi:10.1007/s13132-014-0206-7.

Clinton, L. and Whisnant, R. (2014) Model Behavior 20 Business Model Innovations for Sustainability [online] http://www.sustainability.com/library/modelbehavior\#.VF3umPkZGUk (accessed 20 October 2014).

Dunning, J.H. (1993) The Globalization of Business: The Challenge of the 1990s, Routledge, New York.

Edgeman, R.L. and Eskildsen, J.K. (2012) 'Viral innovation: integration via sustainability \& enterprise excellence', Journal of Innovation \& Business Best Practice, Vol. 12, No. 13, pp.1-13, DOI: $10.5171 / 2012.361451$. 
Enright, M.J. (2002) 'Regional clusters: what we know and what we should know', Paper presented for Kiel Institute International Workshop on Innovation Clusters and Interregional Competition, 12-13 November, Kiel.

Freeman, R.E., Wicks, A.C. and Parmar, B. (2004) 'Stakeholder theory and 'the corporate objective revisited', Organization Science, Vol. 15, No. 3, pp.364-369.

Haanaes, K., Balagopal, B., Kong, M.T., Velken, I., Arthur, D., Hopkins. M.S. and Kruschwitz, N. (2011) 'New sustainability study: the 'embracers' seize advantage', MIT Sloan Management Review [online] http://sloanreview.mit.edu/article/newsustainability-study-the-embracersseize-advantage/ (assessed 15 February 2015).

Hart, S.L. (1995) 'A natural-resource-based view of the firm', Academy of Management Review, Vol. 20, No. 4, pp.986-1014.

Hasna, A.M. (2007) 'Dimensions of sustainability', Journal of Engineering for Sustainable Development: Energy, Environment, and Health, Vol. 2, No. 1, pp.47-57.

Holliday, C. and Pepper, J. (2001) Sustainability Through the Market-Seven Keys to Success, WBCSD, Geneva [online] http://www.wbcsd.org/Pages/EDocument/ EDocumentDetails.aspx?ID=94\&NoSearch ContextKey=true (accessed 10 September 2014).

ILO Report (2007) The Promotion of Sustainable Enterprises [online] http://www.ilo.org/wcmsp5/groups/public/---ed.../wcms_093969.pdf (accessed 15 March 2015).

Johnson, M.W. (2010) Seizing the White Space: Business Model Innovation for Growth and Renewal, Harvard Business Press, Boston.

Krivorotov, V.V., Kalina, A.V. and Tretyakov, V.D. (2013) 'Method of estimation of competitive ability of manufacturing complex', Vestnik $O G U$, Vol. 8, No. 157, pp.34-42.

Lundvall, B-A. and Johnson, B. (1994) 'The learning economy', Journal of Industry Studies, Vol. 1, No. 2, pp.23-42.

Nadella, S. (2014) 'Interview with Satya Nadella', The New York Times [online] http://www.nytimes.com/2014/02/21/business/satya-nadella-chief-of-microsoft-on-hisnewrole.html?_r=0 (accessed 20 February 2014).

Orlitzky, M., Schmidt, F.L. and Rynes, S.L. (2003) 'Corporate social and financial performance: a meta-analysis', Organization Studies, Vol. 24, No. 3, pp.403-441.

Peng, Z.K.L. (2013) 'Towards an internationalized sustainable industrial competitiveness model', Competitiveness Review: An International Business Journal, Vol. 23, No. 2, pp.95-113.

Podobnik, D. and Dolinšek, S. (2008) 'Competitiveness and performance development: an integrated management model', Journal of Organizational Change Management, Vol. 21, No. 2, pp.213-229.

Porter, M.E. (1998) 'Clusters and new economics of competition', Harvard Business Review, November-December, Vol. 76, No. 6, pp.77-90.

Porter, M.E. and Kramer, M.R. (2011) 'Creating shared value', Harvard Business Review, Vol. 89, Nos. 1-2, pp.1-2.

Pratima, B. (2002) 'The corporate challenges of sustainable development', Academy of Management Executive, Vol. 16, No. 2, pp.122-132.

Putsis, W.P. and Dhar, R. (1998) 'The many faces of competition', Marketing Letters, Vol. 9, No. 3, pp.269-284.

Reinert, E. (2009) Industrial Restructuring and Innovation Policy in Central and Eastern Europe Since 1990, The Other Canon Foundation and Tallinn University of Technology Working Papers in Technology Governance and Economic Dynamics.

Santo, B. (1990) Innovation as a Tool for Economic Development: In Russian, Progress, Moscow. 
Solvell, O., Lindqvist, G. and Ketels, C. (2003) The Cluster Initiative Greenbook, The Competitiveness Institute, Gothenburg.

Unruh, G. (2014) Leading the Sustainability Insurgency Big Idea, Sustainability Blog, 10 March [online] http://sloanreview.mit.edu/article/leading-the-sustainability-insurgency/ (accessed 20 January 2015).

Zott, C., Amit, R. and Massa, L. (2011) 'The business model: recent developments and future research', Journal of Management, Vol. 37, No. 4, pp.1019-1042. 